\title{
Influence of Organic Solvents on Cutinase Stability and Accessibility to Polyamide Fibers
}

\author{
CARLA SILVA, ${ }^{1}$ TERESA MATAMÁ, ${ }^{1}$ GEORG M. GUEBITZ, ${ }^{2}$ ARTUR CAVACO-PAULO ${ }^{1}$ \\ ${ }^{1}$ University of Minho, Textile Engineering Department, 4800-058 Guimarães, Portugal \\ ${ }^{2}$ Graz University of Technology, Department of Environment Biotechnology, 8010 Graz, Austria
}

Received 25 November 2004; accepted 13 January 2005

DOI: 10.1002 / pola.20739

Published online in Wiley InterScience (www.interscience.wiley.com).

\begin{abstract}
The stability of cutinase was measured in the presence of dimethylacetamide (DMA) and benzyl alcohol (BA). These solvents are known swelling agents of polyamide fibers. We found that cutinase retains some stability (half-life of $14 \mathrm{~h}$ ), enough for an enzymatic treatment with a solvent composition of $1.5 \%$ DMA $+10 \%$ BA. Enzymatic treatment in the presence of these solvent compositions yields more soluble amino groups as well as more amino end groups at the fiber level. We have shown evidence that the presence of minor quantities of solvent can increase the accessibility of the enzyme towards the polyamide fiber. (ㅇ 2005 Wiley Periodicals, Inc. J Polym Sci Part A: Polym Chem 43: 2749-2753, 2005
\end{abstract}

Keywords: amines; cutinase; hydrolysis; polyamide 6.6; solvents

\section{INTRODUCTION}

Polyamide fibers have a large share of the worldwide market of synthetic fibers. Major characteristics of polyamide fibers are their hydrophobicity and low reactivity with most common chemical agents. ${ }^{1}$ The high hydrophobicity makes these fibers less appropriate to be used in the production of garments that are in contact with human skin. The fiber behavior during textile processing is determined by the orientation grade of polymeric chains, the high crystallinity, and the amino group concentration in terminal positions. Alkaline hydrolysis is an effective way to improve fiber wettability, but the action of concentrated solutions of $\mathrm{NaOH}$ or $\mathrm{KOH}$ is hard to control and extensive damage of the fibers can be sustained. ${ }^{2}$

Previously we have shown ${ }^{3}$ that enzymatic hydrolysis can modify the surface of polyamide

Correspondence to: A. Cavaco-Paulo (E-mail: artur@det. uminho.pt)

Journal of Polymer Science: Part A: Polymer Chemistry, Vol. 43, 2749-2753 (2005) @ 2005 Wiley Periodicals, Inc. fibers by means of hydrolysis of the amide linkages with the formation of amino and carboxylic groups. Superficial changes would improve the fibers' hydrophilicity and their chemical reactivity towards other agents for new finishing effects of polyamide. ${ }^{4}$ Cutinase, from Fusarium solani pisi, was chosen for the modification of polyamide fibers because it is described as serine hydrolase with low specificity and has activity on hydrophobic substrates. ${ }^{4-6}$

Enzymatic action on polyamide fibers causes some superficial cuts along the polymer, corresponding to the breakage of the amide linkages. We have developed previously methodologies to follow the reaction products at the fiber level and in the liquid of the treatment. ${ }^{3}$

The accessibility of the enzyme to the polyamide fibers can be increased by promoting enzymatic hydrolysis in the presence of swelling agents. Organic solvents like benzyl alcohol (BA) and dimethylacetamide (DMA) are generally used in the textile industry of polyamide fibers as dyeing assistants, opening the structure and increasing the rate of dye diffusion. ${ }^{2}$ The major 
interest in solvent addition lies in the possibility of dyeing polyamide fibers at low temperatures when the presence of the solvents claimed to improve the levelness of the dyeing. These solvents can be used as swelling agents to increase enzyme accessibility to polyamide structure. They can act by opening and swelling the rigid structure of polyamide, achieving a plasticization grade where the interchain forces are reduced, and hence the glass transition temperature $\left(\mathrm{T}_{g}\right)$ is lowered. ${ }^{2}$ The technological utility of enzymes can be enhanced greatly by using them in organic solvents rather than in their natural aqueous reaction media. Studies over the past 15 years have revealed not only that this change in solvent is feasible, but also that in such seemingly hostile environments, enzymes can catalyze reactions impossible in water, become more stable, and exhibit new behavior such as "molecular memory."7 However, it is known that organic solvents can denature enzymes. ${ }^{6}$

In this work, we intended to study the stability of cutinase in the presence of benzyl alcohol and dimethylacetamide and measure the hydrolysis extent when cutinase and these organic solvents are used simultaneously. The optimum solvent concentration was at the same time found to apply to the enzymatic treatment of polyamide fabrics.

\section{METHODS}

\section{Materials}

Commercial polyamide (PA 6.6) woven fabric, obtained from Rhodia, taffetá, with $63 \mathrm{~g} \cdot \mathrm{m}^{-2}$, was used in all experiments. Cutinase (GCI 2002/1410) was generously supplied by Genencor International. The reactive dye used, Lanasol Red 5B - C.I. Reactive Red 66-17,555, was generously supplied by CIBA, and the acid dye (C.I. Acid Red 1-18,050) was obtained from Sigma. The organic solvents, benzyl alcohol and dimethylacetamide, were also obtained from Sigma. All other reagents used were laboratory grade reagents.

\section{Stability of Cutinase in Presence of Benzyl Alcohol and Dimetylacetamide}

\section{Assay Conditions}

The enzyme was incubated at a final concentration of $1 \mathrm{mg} / \mathrm{L}$ in phosphate buffer $(50 \mathrm{mM}), \mathrm{pH}$ 8 with $0.05 \%$ of sodium azide, in the presence of several amounts of benzyl alcohol (BA) and dimethylacetamide (DMA) at $35{ }^{\circ} \mathrm{C}$ and $72 \mathrm{rpm}$. For each assay, the final volume was $25 \mathrm{~mL}$, and $50 \mathrm{~mL}$ closed tubes were used as containers. The amounts of organic solvents tested were 0 , $1.5,5,10$, and $15 \%$ of BA and 0,5 , and $10 \%$ of DMA. Measures were taken until the drop of activity was above $50 \%$.

\section{Cutinase Activity}

Cutinase activity was determined using $p$-nitrophenyl butyrate ( $p$-NPB) as a substrate. ${ }^{8}$ For assays with this substrate, $20 \mu \mathrm{L}$ of $p$-NPB $6 \mathrm{mM}$ were added to $1880 \mu \mathrm{L}$ of $50 \mathrm{mM}$ phosphate buffer, $\mathrm{pH} 8$ containing $0.05 \%$ of sodium azide, and then $100 \mu \mathrm{L}$ of bath treatment aliquots were incubated in this reaction media for 1 min., at $35{ }^{\circ} \mathrm{C}$. The hydrolysis was stopped by addition of $2 \mathrm{~mL}$ of acetone. Activity was measured as absorbance at $400 \mathrm{~nm}$. The assays were done in triplicate.

\section{Polyamide Sample Preparation}

To remove some impurities from the fabrics, all polyamide fabric samples used in the experiments were washed with $2 \mathrm{gL}^{-1}$ of a non ionic agent, Lutensol AT $25\left(10 \mathrm{gL}^{-1}\right)$, and water, followed by washing with a $2 \mathrm{gL}^{-1}$ of $\mathrm{Na}_{2} \mathrm{CO}_{3}$ solution, both at $50{ }^{\circ} \mathrm{C}$.

\section{Study of the Influence of Organic Solvents on the Polyamide Structure}

To study the influence of organic solvents on polyamide structure modification, samples of polyamide were dyed with an acid dye in the presence of organic solvents. The conditions of enzymatic treatment in the presence of organic solvents were simulated to measure the extension of the fiber modification caused by the organic solvents. The assays were performed using $2 \mathrm{~g}$ of polyamide samples that were dyed for $4 \mathrm{~h}$ at $35{ }^{\circ} \mathrm{C}$ using a bath ratio of $1: 100$. The dye used was an acid dye (CI Acid Red 1), and the organic solvents used were $1.5 \%$ of benzyl alcohol (BA) and $1.5 \%$ of benzyl alcohol (BA) $+10 \%$ of dimethylacetamide (DMA). Dyeing was performed in sealed, stainless steel dye pots in a laboratory scale textile treatment machine (Rotawash) at $20 \mathrm{rpm}$. After dyeing the samples were washed with $2 \mathrm{mLL}^{-1}$ of a Lutensol solution $\left(10 \mathrm{gL}^{-1}\right)$ 
at $60{ }^{\circ} \mathrm{C}$ followed by washing with tap water. All experiments were performed in duplicate.

\section{Enzymatic Treatment of Polyamide Fabrics in Presence of Organic Solvents}

To measure the hydrolysis extent of enzymatic action, samples of polyamide were incubated with cutinase in the presence of organic solvents.

The assay was performed using $1 \mathrm{~g}$ of polyamide fabric that was incubated with $6.69 \mu \mathrm{g} \mathrm{mL}^{-1}$ of enzyme and different concentrations of organic solvents (1.5\% of benzyl alcohol and $1.5 \%$ of benzyl alcohol $+10 \%$ of dimethylacetamide) at $35{ }^{\circ} \mathrm{C}$ using phosphate buffer $(\mathrm{pH}=8 ; 50 \mathrm{mM})$ for $4 \mathrm{~h}$. Aliquots were taken at different times of incubation ( 1 and $4 \mathrm{~h}$ ) for each enzyme concentration assayed for posterior chemical analysis, and samples of fabric were taken at $4 \mathrm{~h}$ of treatment for posterior dyeing. A bath ratio of 1:200 was used. The enzymatic treatment was performed in sealed, stainless steel dye pots of $250 \mathrm{~cm}^{3}$ in a laboratory scale dyeing machine (vertical agitation simulating European washing machinesRotawash). After enzymatic treatment, all samples were washed with a $2 \mathrm{gL}^{-1} \mathrm{Na}_{2} \mathrm{CO}_{3}$ solution for $1 \mathrm{~h}$ at $60{ }^{\circ} \mathrm{C}$ followed by washing with water for $1 \mathrm{~h}$ at $60{ }^{\circ} \mathrm{C}$. The washes were performed in a Rotawash machine. All experiments were performed in duplicate.

\section{Determination of the Amino End Groups at the Fiber Surface by Dyeing with a Reactive Dye}

Enzymatic hydrolysis yields amino groups at the surface of the polyamide fibers, and their presence can be detected by dyeing with a wool reactive dye, specific for the primary amino groups. Standard reactive dyeing fixes the chromophoric structures to hydroxyl groups of the fibers. In the case of polyamide, the free amino groups at the surface of the fibers are detected by the specific reaction with the $\alpha$-bromoacrylamido dye reactive group. ${ }^{9}$ The reactive dyeing methodology was based on the method already described by us. ${ }^{3}$

\section{Determination of Amino Groups in the Bath Solution Treatment}

To follow the formation of amino groups and quantify these groups present in the treatment liquid, the trinitrobenzenesulfonic acid (TNBS) method was adapted from a methodology described by others. ${ }^{10}$ This method is based on the reaction of the primary amino groups with the sodium salt of trinitrobenzenesulfonic acid (TNBS), and it was already described by us. ${ }^{3}$

\section{RESULTS AND DISCUSSION}

\section{Cutinase Stability in Presence of Organic Solvents}

To measure cutinase stability in the presence of organic solvents (benzyl alcohol and dimethylacetamide), the enzyme activity at different periods of incubation was measured and the half-life time was determined.

Analyzing the results of Table 1, it can be seen that in the presence of percentages of benzyl alcohol above $1.5 \%$, cutinase enzyme loses all activity in the first hour of incubation. For $1.5 \%$ of benzyl alcohol, the activity decreases when compared with the value of the control, but this amount of solvent does not denature the enzyme. One can observe also that the halflife time of the enzyme in the presence of benzyl alcohol $(1.5 \%)$ is higher than in the presence of dimethylacetamide. When we tested the two solvents simultaneously, the half-life time decreased, although in the case of $1.5 \%$ of $\mathrm{BA}+$ $10 \%$ of DMA, there is a slight increase that corresponds to a half of the value obtained for $1.5 \%$ of BA. The results obtained are not fully understood yet, but the probable explanation can be based on the hydrophobicity of the pair enzyme/organic solvent. Hydrophobic solvents are usually superior to hydrophilic ones when used as enzymatic reaction media because the

Table 1. Stability of Cutinase in Presence of Organic Solvents

\begin{tabular}{lc}
\hline \multicolumn{1}{c}{ Organic solvent } & $\begin{array}{c}\text { Half-Life time } \\
\text { (hours) }\end{array}$ \\
\hline Water & 35 \\
$1.5 \%$ benzyl alcohol & 26 \\
$5 \%$ benzyl alcohol & $<1$ \\
$10 \%$ benzyl alcohol & $<1$ \\
$15 \%$ benzyl alcohol & $<1$ \\
$5 \%$ dimethylacetamide & 11 \\
$10 \%$ dimethylacetamide & 12 \\
$1.5 \%$ benzyl alcohol & \\
$\quad+10 \%$ dimethylacetamide & 14 \\
$10 \%$ benzyl alcohol & \\
$+10 \%$ dimethylacetamide & $<1$ \\
\hline
\end{tabular}




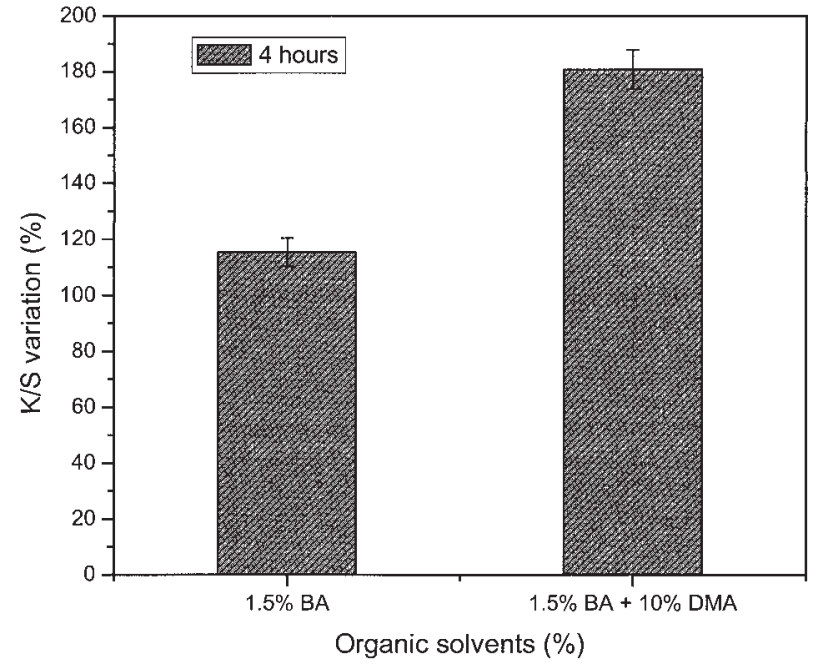

Figure 1. Color level variation of fabrics treated with solvents $(4 \mathrm{~h})$ relative to fabrics treated with water $(4 \mathrm{~h})$ at $35{ }^{\circ} \mathrm{C}$; dyeing was performed with CI Acid Red 1 .

latter have a greater tendency to strip tightly bound water (which is essential for catalytic activity) from the enzyme molecules. ${ }^{7}$ Low percentages of benzyl alcohol $(<1.5 \%)$ have a great affinity to the active site of the cutinase enzyme, which is also hydrophobic. However, the use of low amounts of benzyl alcohol on the system does not affect the enzyme activity, which is maintained on acceptable values. When higher amounts of benzyl alcohol are used, the great affinity of this solvent to the active site of the enzyme might affect the internal structure of the enzyme, causing its denaturation. On the other hand, when dimethylacetamide is used, the decrease of activity is probably due to the tendency of this solvent to strip tightly bound water from the enzyme molecules. Regarding this, the enzyme becomes more rigid and loses its absolute activity but the stability is somehow maintained.

\section{Polyamide Fibers Accessibility in Presence of Organic Solvents}

To measure the accessibility of the organic solvents to the polyamide structure, fabric samples were dyed for $4 \mathrm{~h}$ at $35{ }^{\circ} \mathrm{C}$ with an acid dye (CI Acid Red 1) in the presence of organic solvents (Fig. 1). Analyzing the results, one can see that the combined action of benzyl alcohol and dimethylacetamide has the more pronounced effect on polyamide structure. It might occur because the latter strips the bound water, and access to the internal structure of the fiber, by the first one, is improved. In the presence of benzyl alcohol, the samples dyed with acid dye show an increase above $100 \%$ of K/S. The samples dyed in the presence of a combined action of benzyl alcohol and dimethylacetamide show an increase of K/S percentage above $150 \%$. The organic solvents act on the polyamide fiber like swelling agents, opening the structure that becomes more accessible to the dye that penetrates into the fiber structure. The color differences are measured by spectral values determination and are presented in Figure 1.

\section{Determination of Soluble Amino Groups in the Bath Solution Treatment}

The cutinase treatment of polyamide yields carboxylic and amino groups resulting from the cleavage of the amide bonds of the fiber chains. These groups can be found in the surface of the treated fabric or in the liquid of treatment. The amino groups resulting from the polyamide hydrolysis were measured spectrophotometricaly as described before. ${ }^{3}$ The amount of soluble amino groups produced after 1 and $4 \mathrm{~h}$ of incubation is shown in Figure 2. One can see that after $4 \mathrm{~h}$ of incubation, a concentration of amines was produced with a maximum of $0.15 \mathrm{mM}$, in the case of samples treated with cutinase. As expected, the organic solvents action increased enzyme accessibility into the fiber; this can be seen by the increase of the enzyme protein adsorption (Table 2), as well as by

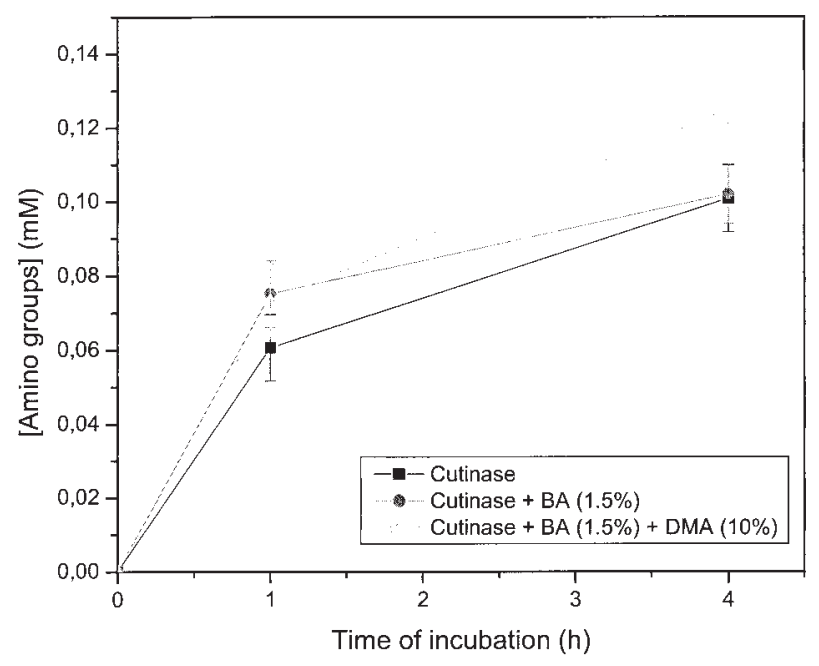

Figure 2. Concentration of primary amino groups in the liquid of treatment of polyamide samples $\left(0.20 \mathrm{UL}^{-1}\right.$ of protein; $\mathrm{T}=35{ }^{\circ} \mathrm{C}$ using a Rotawash machine). 
an increase of the amino groups produced (Fig. 2). The amount of amino groups formed in these cases $(1.5 \%$ of BA and $1.5 \%$ of BA $+10 \%$ of DMA) is higher than the one obtained only with cutinase enzyme. These results confirm a better accessibility of the enzyme to the fiber (Fig. 2).

\section{Determination of Amino End Groups at Fiber Surface by Reactive Dyeing}

In our previous work, we have shown that the grade of conversion of cutinase is low in synthetic substrates. ${ }^{3}$ The polyamide hydrolysis was promoted using cutinase in the presence of organic solvents for $4 \mathrm{~h}$, and the treated samples were dyed at $50{ }^{\circ} \mathrm{C}$ with a reactive dye, specific to react with the primary amino groups formed. The reason for which a low temperature $\left(50{ }^{\circ} \mathrm{C}\right)$ was chosen is the fact that above this value the polyamide structure is more open and the amino groups formed by enzymatic action might be hidden in the interior of the fiber. ${ }^{3}$ The spectral values obtained are shown in Figure 3. Comparing the K/S values of samples treated with cutinase and samples treated with cutinase in the presence of benzyl alcohol + dimethylacetamide, it can be seen that organic solvents' action can improve the enzymatic hydrolysis. The accessibility of the enzyme to the fiber increases, and the enzymatic action might occur, not only at the surface of the fiber, but also at a more hidden part of the structure.

\section{CONCLUSIONS}

It can be concluded that the activity of the cutinase enzyme is preserved in the presence of low amounts of benzyl alcohol and dimethylacetamide. Polyamide fibers become more open structures and more suitable to be modified by cutinase action. The percentage of benzyl alcohol and dimethylacetamide was optimized to improve the enzymatic treatment of the fibers. The cutinase enzyme's accessibility to the polyamide structure

Table 2. Percent of Protein Adsorbed by the Fiber in Presence of Organic Solvents

Enzymatic treatment $\%$ of adsorption

Enzyme
Enzyme $+1.5 \%$ BA
Enzyme $+\mathbf{1 . 5} \%$ BA $+\mathbf{1 0} \%$ DMA

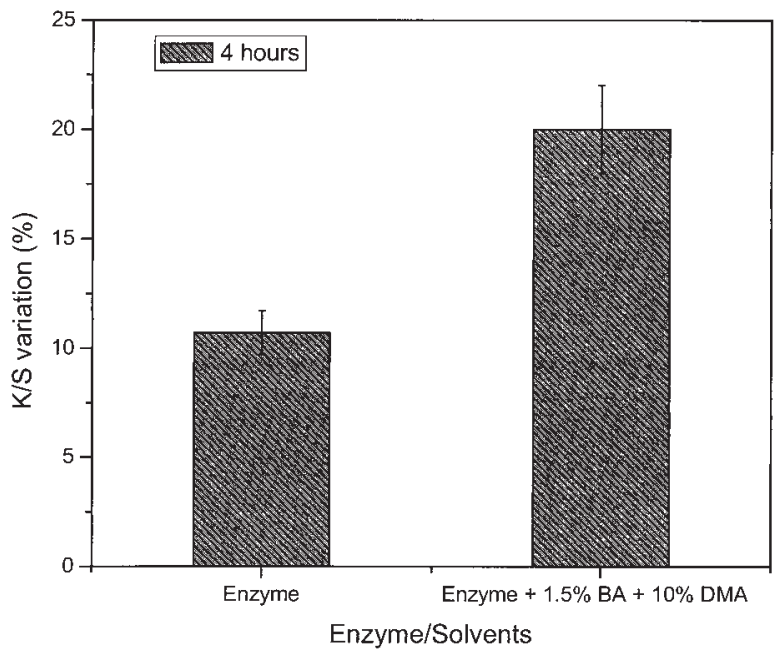

Figure 3. Increase of fiber amino end groups as K/S (\%) at $50{ }^{\circ} \mathrm{C}$ on samples treated for $4 \mathrm{~h}$ and dyed with Lanasol Red 5B (C.I. Reactive Red 66).

increases in the presence of these solvents, and it can be seen as an increase of the amino groups formed, in solution or at the fiber surface.

The low amounts of solvents used (less than 10 for DMA and $1.5 \%$ for $\mathrm{AB}$ ) will not present environmental concerns in the face of achieved benefits like low process time and high amount of amino groups produced.

\section{REFERENCES AND NOTES}

1. Lewin, M.; Pearce, E. M. In Handbook of Fiber Chemistry; Marcel Dekker: New York, 1998; Chapter 2, pp. 72-73.

2. Burkinshaw, S. M. In Chem Principles of Synthetic Fibre Dyeing; Blackie Academica \& Professional: London, 1995; Chapter 2, pp 77-100.

3. Silva, C.; Cavaco-Paulo, A. Biocatal Biotrans 2004, 22, 357-360.

4. Silva, C.; O’Neill, A.; Carneiro, F.; Fonseca, L.; Cabral, J.; Cavaco-Paulo, A. J Polym Sci Part A: Polym Chem 2005, 43, 2448-2450.

5. Carvalho, C. M. L.; Aires-Barros, M. R.; Cabral, J. Biotechnol Bioeng 1999, 66, 17.

6. Soares, C. M.; Teixeira, V.; Baptista, H.; António, M. Biophys J 2003, 84, 1628.

7. Klibanov, A. M. Nature 2001, 409, 241.

8. Shirai, K.; Jackson, R. L. J Biol Chem 1982, 257, 1253.

9. Lewis, D. M. In Wool Dyeing; Society of Dyers and Colourists: Bradford, England, 1992; pp 226227.

10. Morçöl, T.; Subramanian, A.; Velander, W. H. J Immunol Methods 1997, 203, 45-53. 